Check for updates

${ }^{1}$ NHS Grampian, Aberdeen, UK

${ }^{2}$ Department of Psychology,

National University of Ireland,

Galway, Ireland

${ }^{3}$ Department of Psychology. University of Aberdeen, UK

${ }^{4}$ Institute of Applied Health

Sciences, University of

Aberdeen, UK

Correspondence to: R T Staff,

Aberdeen Royal Infirmary,

Aberdeen AB25 2ZH, UK:

r.staff@abdn.ac.uk

Additional material is published online only. To view please visit

the journal online.

Cite this as: BMJ 2018;363:k4925 http://dx.doi.org/10.1136/bmj.k4925

Accepted: 20 November 2018

\section{Intellectual engagement and cognitive ability in later life (the "use it or lose it" conjecture): longitudinal, prospective study}

\author{
Roger T Staff, ${ }^{1}$ Michael J Hogan, ${ }^{2}$ Daniel S Williams, ${ }^{3}$ L J Whalley ${ }^{4}$
}

\section{ABSTRACT \\ OBJECTIVES}

To examine the association between intellectual engagement and cognitive ability in later life, and determine whether the maintenance of intellectual engagement will offset age related cognitive decline.

DESIGN

Longitudinal, prospective, observational study.

SETTING

Non-clinical volunteers in late middle age (all born in 1936) living independently in northeast Scotland.

PARTICIPANTS

Sample of 498 volunteers who had taken part in the

Scottish Mental Health Survey of 1947, from one birth year (1936).

\section{MAIN OUTCOME MEASURES}

Cognitive ability and trajectory of cognitive decline in later life. Typical intellectual engagement was measured by a questionnaire, and repeated cognitive measurements of information processing speed and verbal memory were obtained over a 15 year period (recording more than 1200 longitudinal data points for each cognitive test).

RESULTS

Intellectual engagement was significantly associated with level of cognitive performance in later life, with each point on a 24 point scale accounting for 0.97 standardised cognitive performance (IQ-like) score, for processing speed and 0.71 points for memory (both $\mathrm{P}<0.05)$. Engagement in problem solving activities had the largest association with life course cognitive gains, with each point accounting for 0.43 standardised cognitive performance score, for processing speed and 0.36 points for memory (both $\mathrm{P}<0.05$ ). However, engagement did not influence the trajectory of age related decline in

\section{WHAT IS ALREADY KNOWN ON THIS TOPIC}

The "use it or lose it" conjecture refers to the belief that cognitive function can be maintained or enhanced by exercising that function, offsetting cognitive decline in later life

The conjecture is widely accepted by healthcare professionals and the public

\section{WHAT THIS STUDY ADDS}

This study used repeated cognitive measures in a well characterised sample of volunteers drawn from one birth year (1936)

Self reported intellectual engagement had no influence on the trajectory of decline of memory and processing speed

Engagement in intellectual stimulating activities was associated with early life ability, but also had no association with the trajectory of decline in later life Engagement in problem solving activities had the largest association with life course cognitive gains cognitive performance. Engagement in intellectual stimulating activities was associated with early life ability, with correlations between engagement and childhood ability and education being 0.35 and 0.22 , respectively (both $\mathrm{P}<0.01$ ).

\section{CONCLUSION}

These results show that self reported engagement is not associated with the trajectory of cognitive decline in late life, but is associated with the acquisition of ability during the life course. Overall, findings suggest that high performing adults engage and those that engage more being protected from relative decline.

\section{Introduction}

Loss of mental competence can cause substantial anticipatory concern among older adults (that is, age> 65 years) by suggesting that such loss heralds the onset of progressive cognitive decline and dementia. ${ }^{1}$ Public health guidance on successful ageing highlights the importance of social and physical activity and engagement. $^{2}$ Cognitive endeavours that engage multiple activity domains might have important benefits. ${ }^{3}$ However, longitudinal analysis of potential protective effects of cognitively effortful pursuits is difficult and a variety of methodological challenges have been documented. In studies ${ }^{4}$ that track cognitive change in adulthood, there are a dearth of historical data on childhood mental ability and limited awareness that early performances on IQ-type tests are already confounded by reading proficiency acquired before IQ-type scores can be obtained.

Another concern is the potential practice effects that can result from exposure to a common test format, and the possibility that differences in initial cognitive ability influence the size of practice effects observed. ${ }^{5}$ Results presented by Wesnes and Pincock in $2002^{6}$ suggest that improvements in practice effects for commonly used tests of processing speed and memory are largest between the first and second occasion, with little improvement after that. Modelling of longitudinal data allows such practice effects to be accounted for by an initial practice model. ${ }^{7}$ Finally, reports of the effects of additional common confounders such as education and sex on cognitive performance are mixed, but it is generally accepted that education and sex affect cognitive performance in particular domains ${ }^{8}$ and early education has an influence across the life course. ${ }^{9}$

Activity engagement is so often argued to be an important dimension of successful ageing ${ }^{10}$ (and more specifically, the preservation of intellectual function in old age ${ }^{11-17}$ ) that the "use it or lose it" conjecture already appears to be an established fact of cognitive ageing. We aimed to re-examine this claim 
by analysing the effects of activity engagement on cognitive test performance and the trajectory of that performance in late adulthood. In addition, we aimed to test the robustness of observations by controlling for life course cognition and education.

Various studies support the "use it or lose it" conjecture. For example, Stanovich and colleagues proposed in 1995 that literary habits and exposure to print might be one way in which cognitive capacities are maintained with age. ${ }^{18}$ In their cross sectional study including a sample of younger and older adults, the researchers found that measures of exposure to print was associated with the positive relations between age and vocabulary, and between age and declarative knowledge. In 1997, Christensen and colleagues assessed the influence of self reported and informant reported activity levels on crystallised intelligence, fluid intelligence, memory, and mini-mental state examination scores in a sample of community dwelling, older participants. They found that specific activities were associated with higher cognitive performance in less well educated participants, but had no effect on cognitive performance in highly educated participants. ${ }^{12}$ In 2003, Verghese and colleagues conducted a prospective cohort study of older adults who resided in the community and did not have dementia at baseline. ${ }^{17}$ They reported that even after statistically controlling for educational level, presence or absence of chronic medical illnesses, and baseline cognitive status, those individuals who participated at least twice weekly in cognitive activities such as reading, playing board games, and playing musical instruments had significantly reduced risks for dementia. $^{13}$

Our collaborators, who studied survivors sampled from the Scottish Mental Surveys, have also examined possible links between activity engagement and cognitive functioning in later life. Their study identified typical intellectual engagement scores (recorded on a self report questionnaire) and childhood mental ability as powerful effects on verbal fluency scores in late life. ${ }^{19}$ The evidence is clear that there is an association between typical intellectual engagement and cognitive ability in late life, although data on the longitudinal trajectory of cognitive change are sparse. However, the strength of any association between engagement and cognition is unclear, and it may well be that both cognition and engagement share a common origin (eg, early ability or education).

With access to archives of childhood mental ability and repeated measurement of cognitive ability in late adulthood, we aimed to investigate the possible effects of childhood ability, education, sex, and practice as a result of repeated cognitive testing when investigating the influence of typical intellectual engagement on late life cognition and the trajectory of decline. We analysed trajectories for two cognitive tests used repeatedly on our study group: the auditory verbal learning test as an indicator of memory performance, and the digit symbol substitution test as a measure of mental speed. Both tests are known to be sensitive to the effects of ageing and are measures of fluid ability. ${ }^{20}$

\section{Methods}

\section{Participants}

The sample of older adults with retained childhood intelligence scores or data was drawn from the archives of the Scottish Council for Research in Education, which had maintained population based records of the Scottish Mental Surveys of 1947. All children born in 1936 and who were at school in Scotland on 4 June 1947 when aged $11( \pm 0.5)$ years took part in a group administered intelligence test (the Moray house test). More than $95 \%$ of eligible Scottish children were surveyed and scores retained. ${ }^{21}$ A subset of these participants were recruited into a longitudinal study of ageing at around 64 years of age and were recalled for testing on up to five occasions over a 15 year period. Figure 1 shows a flowchart of study recruitment and retention.

\section{Cognitive tests}

Current adult ability was assessed by a trained psychologist following standard procedures using the digit symbol substitution test and the auditoryverbal learning test. ${ }^{22}$ The digit symbol substitution test requires participants to match symbols with a corresponding digit; the total number of correct answers provided the test score. The auditory-verbal learning test is widely used to evaluate verbal memory and reliably identifies older adults with age related memory impairments. ${ }^{23}$ This test was administered to the study participants on the first occasion at about age 64 years and repeated on up to five occasions over the next 14 years. Results from the national adult reading test were recorded on study entry, and provide an estimate of crystallised intelligence. ${ }^{24}$

\section{Education}

Demographic data were obtained from participants on recruitment in a structured interview at age 64 $( \pm 1)$ years by a trained research nurse. Education was recorded as the total number of years spent in formal education before age 25 years.

\section{Typical intellectual engagement}

We used a 16 question subset of the questionnaire for typical intellectual engagement. ${ }^{25}$ This tool has been used to estimate intellectual engagement in various studies, has been predominantly used to predict academic performance, and has shown to predict performance over and above intelligence and personality traits. ${ }^{26}$ Its reliability has been assessed by von Stumm and colleagues ${ }^{27}$ in a meta-analysis with a mean estimate of reliability of more than 0.8 . Typical intellectual engagement has been compared with other scales of intellectual engagement and curiosity such as the epistemic curiosity scale and the need for cognition scale, and has strongly correlated with both (Pearson correlations of 0.86 and 0.71 , 
respectively). ${ }^{28}$ The activity domains and associated scale questions used were:

- Reading (questions 22, 29, 44, 52): estimates the interest in, activity, and enjoyment gained from reading.

- Problem solving (questions 12, 36, 37, 56): assesses an individual's disposition to participate in and enjoy complicated problem solving.

- Abstract (questions 3, 14, 30, 42): estimates an individual's propensity to consider ideas and concepts in depth.

- Intellectually curious (questions 10, 16, 20, 27): assesses an individual's predisposition to learn about new topics through various media.

An overall typical intellectual engagement score was constructed as the sum of all 16 responses. Questions are shown in supplementary materials 1 , with the score for each response.

\section{Statistical analysis}

Test scores and statistical model

The raw scores from the digit symbol substitution and auditory-verbal learning tests were standardised to a

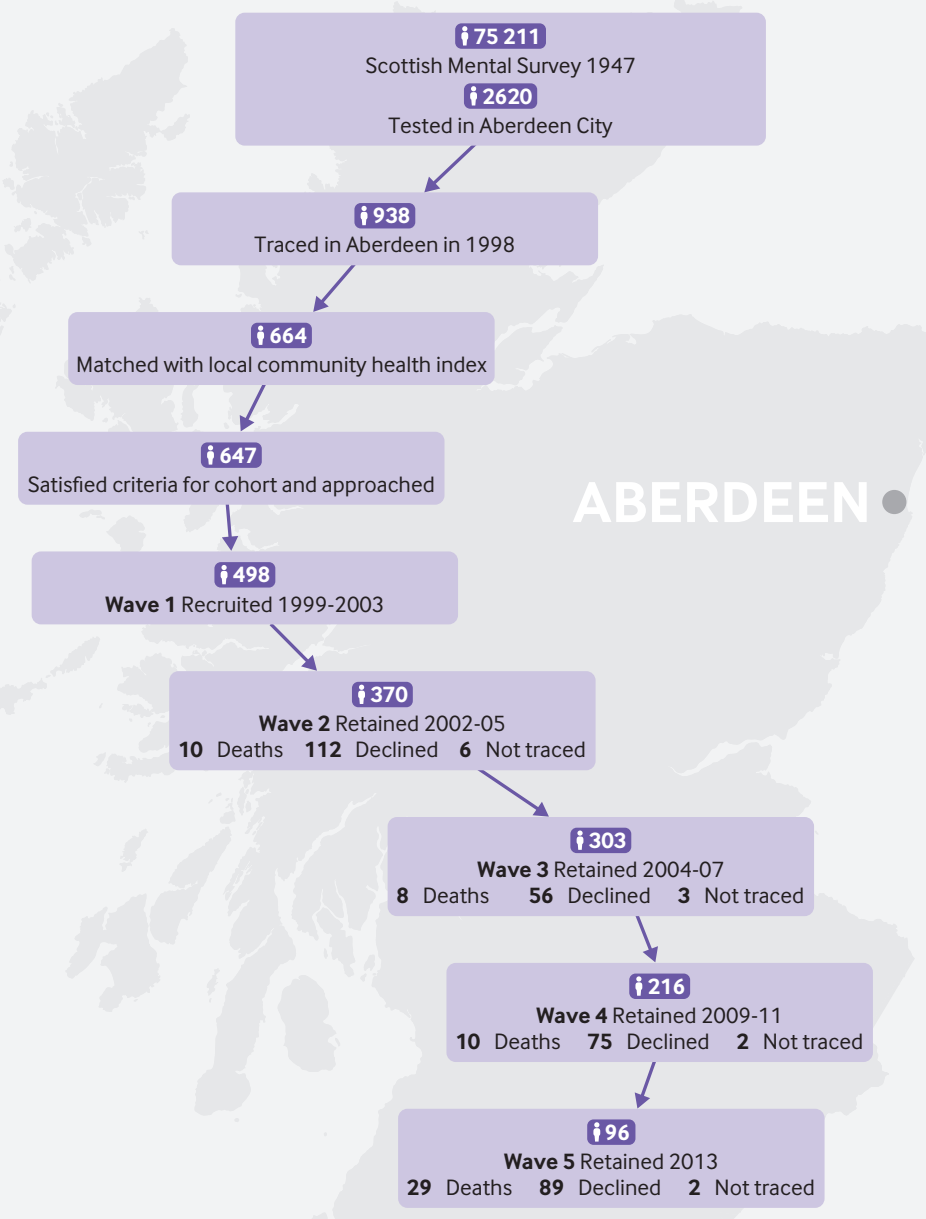

Fig 1 | Recruitment, retention, and attrition in follow-up study of the 1947 mental survey of Aberdeen schoolchildren mean of 100 and a standard deviation of 15 to produce an IQ-like scale. Age at testing was the number of years after participants' 60th birthdays. We modelled age in this form so that the intercept occurred at age 60 years rather than zero years, such that the calculation for the intercept would represent a realistic adult value rather than one extrapolated 64 years earlier. Because our sample were all born in the same year and tested at a similar age, a confounder for age at entry was not used. We modelled cognitive performance with a linear mixed model, as a combination of age at testing, sex, practice, and typical intellectual engagement domain (modelled separately). In addition, we included an interaction term of age and typical intellectual engagement (agexTIE). For each model, a probability value of $\mathrm{P}<0.05$ was considered significant.

In our model, we hypothesised that our data for longitudinal cognitive performance could be modelled as a linear combination of age and sex of the participant, the gains realised through practice by taking the test more than once, the level of intellectual engagement of participants, and the interaction between age and engagement. Owing to the complex nature of our longitudinal data, we used a mixed model to further understand the influence or measures on cognition and cognitive trajectory (supplementary materials 2). Here, $i$ represented the occasion of testing; $j$ the individual being tested; $\beta_{0 j}$ the intercept; $\beta_{1 j}$ the slope with age; and $e_{i,}$ the residual. The intercept and slope with age ( $\beta_{0 j}$ and $\beta_{1 j}$, respectively) modelled both fixed and random effects. The random departure form $\beta_{0}$ (at the individual level); $u_{0 j}$ was constructed so that it had a mean of zero and a variation of $\sigma_{0}{ }^{2}$; similarly, $\beta_{1}$ represented the fixed part of the slope and $u_{1 j}$ the random departure form $\beta_{1}$ (at the individual level); $u_{1 j}$ was constructed so that it had a mean of zero and a variation $\sigma_{1 j}{ }^{2}$.

In post hoc analyses, we examined the independence of all significant measures of typical intellectual engagement after adjusting for crystallised ability, national adult reading test scores $\left(\beta_{5 j}\right)$, education $\left(\beta_{6 j}\right)$, and childhood intelligence scores on the Moray house test $\left(\beta_{7 j}\right)$.

\section{Patient and public involvement}

Before recruitment and throughout this project, participants and the public were involved through open public meetings with presentations and question and answer sessions, where their views and ideas were considered. The results of the project were disseminated at these follow-up public meetings, via the usual academic media and in the local press. Lay members of the steering group were recruited and were present at several group meetings.

\section{Results}

The study sample is described in table 1. Comparisons between sexes showed that women scored better on the digit symbol substitution test and on typical intellectual engagement, with higher scores for abstract reasoning engagement and reading engagement. Primary 


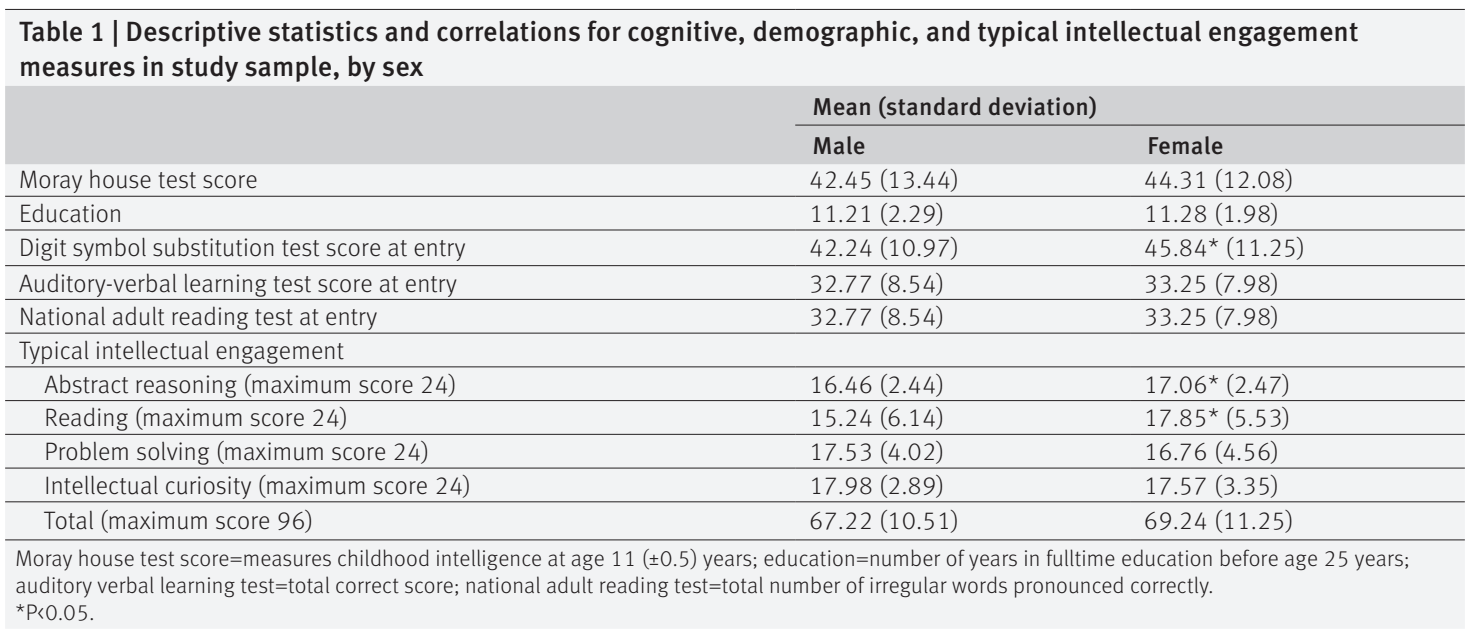

analysis indicated that the early life measures were associated with engagement. The Pearson's correlation between total typical intellectual engagement and the Moray house score was $0.35(\mathrm{P}<0.01)$ and between total typical intellectual engagement and education was $0.22(\mathrm{P}<0.01)$.

The typical intellectual engagement models for each domain are shown in table 2 and indicated an expected significant decline in cognitive performance with age, ranging from -1.09 to -1.31 standard points per year for the digit symbol substitution test and -0.77 to -1.69 for the auditory-verbal learning test. Women performed better than men on both tests (about 5-7 and about 8-10 standard points, respectively), and each test demonstrated a significant practice effect (about 3.6 and about 4.6 standard points, respectively). The results also show that the problem solving domain had a significant positive fixed effect on both cognitive scores (about 1.0 and about 0.7 standard points, respectively). The total score for typical intellectual engagement also had a significant positive fixed effect, which appeared smaller (about 0.29 and about 0.23 standard points, respectively). None of the age $\times$ TIE interaction terms were significant, indicating that intellectual engagement did not influence the trajectories of age decline.

Introducing original life course measures (childhood intelligence, education, and national adult reading test scores) into the model and removing the interaction term (table 3) showed that only the problem solving domain of typical intellectual engagement remained significant for both the digit symbol substitution

\begin{tabular}{|c|c|c|c|c|c|}
\hline & \multicolumn{5}{|c|}{ Activity domains of TIE } \\
\hline & Reading & Problem solving & Abstract reasoning & Intellectual curiosity & Total TIE \\
\hline \multicolumn{6}{|c|}{ Digit symbol substitution test } \\
\hline$\beta_{0 j}$ & $98.5(2.8)^{\star}$ & $85.5(3.8)^{\star}$ & $97.2(6.5)^{\star}$ & $93.0(5.6)^{\star}$ & $82.9(5.9)^{\star}$ \\
\hline$\beta_{1 j}$ (age) & $-1.27(0.23)^{\star}$ & $-1.24(0.31)^{\star}$ & $-1.12(0.52)^{\star}$ & $-1.09(0.43)^{\star}$ & $-1.31(0.48)^{\star}$ \\
\hline$\beta_{2 j}(\operatorname{sex})$ & $5.43(1.55)^{\star}$ & $6.94(1.46)^{\star}$ & $6.09(1.52)^{\star}$ & $6.46(1.52)^{\star}$ & $5.65(1.49)^{\star}$ \\
\hline$\beta_{3 j}$ (practice) & $3.65(0.53)^{\star}$ & $3.66(0.53)^{\star}$ & $3.66(0.53)^{\star}$ & $3.66(0.53)^{\star}$ & $3.66(0.53)^{\star}$ \\
\hline$\beta_{4 j}(\mathrm{TIE})$ & $0.26(0.16)$ & $0.97(0.21)^{\star}$ & $0.32(0.38)$ & $0.52(0.30)$ & $0.29(0.09)^{\star}$ \\
\hline$\beta_{5 j}($ age $\times$ TIE $)$ & $0.006(0.212)$ & $0.004(0.017)$ & $-0.003(0.003)$ & $-0.004(0.023)$ & $0.002(0.007)$ \\
\hline$u_{0 j}$ (intercept) & $229.2(23.3)^{\star}$ & $213.4(22.1)^{\star}$ & $231.9(23.5)^{\star}$ & $229.8(23.3)^{\star}$ & $221.2(22.7)^{\star}$ \\
\hline$\rho_{0,1}$ (age, intercept) & $-4.15(1.37)^{\star}$ & $-4.12(1.34)^{\star}$ & $-4.23(1.39)^{\star}$ & $-4.19(1.38)^{\star}$ & $-4.10(1.36)^{\star}$ \\
\hline$u_{1 j}$ (age) & $0.40(0.11)^{\star}$ & $0.40(0.11)^{\star}$ & $0.41(0.11)^{\star}$ & $0.41(0.11)^{\star}$ & $0.40(0.10)^{\star}$ \\
\hline$e_{i, j}$ & $34.3(2.1)^{\star}$ & $34.3(2.1)^{\star}$ & $34.2(2.1)^{\star}$ & $34.2(2.1)^{\star}$ & $34.3(2.1)^{\star}$ \\
\hline$-2 \times$ loglikelihood & 7970.0 & 7941.7 & 7974.8 & 7971.8 & 7956.5 \\
\hline \multicolumn{6}{|c|}{ Auditory-verbal learning test } \\
\hline$\beta_{0 j}$ & $92.6(2.5)^{\star}$ & $84.1(3.5)^{\star}$ & $93.8(5.8)^{\star}$ & $90.3(5.1)^{\star}$ & $81.1(5.4)^{\star}$ \\
\hline$\beta_{1 j}$ (age) & $-0.83(0.28)^{\star}$ & $-0.77(0.37)^{\star}$ & $-1.69(0.64)^{\star}$ & $-0.86(0.55)$ & $-1.32(0.60)^{\star}$ \\
\hline$\beta_{2 j}(\operatorname{sex})$ & $8.22(1.31)^{\star}$ & $9.71(1.25)^{\star}$ & $8.91(1.29)^{\star}$ & $9.36(1.29)^{\star}$ & $8.60(1.26)^{\star}$ \\
\hline$\beta_{3 j}$ (practice) & $4.62(0.68)^{\star}$ & $4.63(0.68)^{\star}$ & $4.66(0.68)^{\star}$ & $4.63(0.68)^{\star}$ & $4.64(0.68)^{\star}$ \\
\hline$\beta_{4 j}(\mathrm{TIE})$ & $0.26(0.14)$ & $0.71(0.19)^{\star}$ & $0.17(0.34)$ & $0.34(0.28)$ & $0.23(0.08)^{\star}$ \\
\hline$\beta_{5 j}($ age $\times$ TIE $)$ & $0.015(0.015)$ & $0.012(0.02)$ & $0.066(0.037)$ & $0.016(0.03)$ & $0.011(0.008)$ \\
\hline$u_{0 j}$ (intercept) & $104.8(18.1)^{\star}$ & $98.1(17.6)^{\star}$ & $107.8(18.3)^{\star}$ & $107.1(18.3)^{\star}$ & $100.8(17.8)^{\star}$ \\
\hline$\rho_{0,1}$ (age, intercept) & $-0.66(1.48)$ & $-0.69(1.46)$ & $-0.75(1.49)$ & $-0.67(1.49)$ & $-0.79(1.47)$ \\
\hline$u_{1 j}$ (age) & $0.58(0.16)^{\star}$ & $0.57(0.16)^{\star}$ & $0.59(0.17)^{\star}$ & $0.58(0.17)^{\star}$ & $0.57(0.16)^{\star}$ \\
\hline$e_{i, j}$ & $59.1(3.5)^{\star}$ & $59.2(3.6)^{\star}$ & $58.9(3.5)^{\star}$ & $59.2(3.6)^{\star}$ & $59.1(3.6)^{\star}$ \\
\hline$-2 \times \log l i k e l i h o o d$ & 8397.3 & 8379.7 & 8400.6 & 8403.9 & 8381.8 \\
\hline
\end{tabular}




\begin{tabular}{|c|c|c|c|c|c|}
\hline & \multicolumn{5}{|c|}{ Activity domains of TIE } \\
\hline & Reading & Problem solving & Abstract reasoning & Intellectual curiosity & Total TIE \\
\hline \multicolumn{6}{|c|}{ Digit symbol substitution test } \\
\hline$\beta_{0 .}$ & $39.4(5.2)^{*}$ & $36.9(5.3)^{\star}$ & $41.2(6.4)^{\star}$ & $38.9(6.0)^{\star}$ & $38.3(5.7)^{\star}$ \\
\hline$\beta_{1 j}$ (age) & $-1.20(0.09)^{*}$ & $-1.20(0.09)^{\star}$ & $-1.20(0.09)^{\star}$ & $-1.20(0.09)^{\star}$ & $-1.20(0.09)^{\star}$ \\
\hline$\beta_{2 j}(\mathrm{sex})$ & $5.43(1.32)^{\star}$ & $5.52(1.28)^{\star}$ & $5.18(1.29)^{\star}$ & $5.13(1.29)^{\star}$ & $5.07(1.29)^{\star}$ \\
\hline$\beta_{3 j}$ (practice) & $3.73(0.53)^{\star}$ & $3.72(0.53)^{\star}$ & $3.73(0.53)^{*}$ & $3.73(0.53)^{\star}$ & $3.73(0.53)^{\star}$ \\
\hline$\beta_{4 j}(\mathrm{TIE})$ & $-0.13(0.11)$ & $0.43(0.16)^{\star}$ & $-0.14(0.26)$ & $0.03(0.22)$ & $0.03(0.07)$ \\
\hline$\beta_{5 j}$ (NART) & $0.15(0.06)^{*}$ & $0.12(0.06)^{*}$ & $0.14(0.06)^{\star}$ & $0.14(0.06)^{*}$ & $0.13(0.06)^{\star}$ \\
\hline$\beta_{6 j}$ (education) & $0.42(0.06)^{\star}$ & $0.39(0.07)^{\star}$ & $0.42(0.07)^{\star}$ & $0.42(0.07)^{\star}$ & $0.41(0.07)^{\star}$ \\
\hline$\beta_{7 j}(\mathrm{MHT})$ & $-0.13(0.11)$ & $0.43(0.16)^{\star}$ & $-0.14(0.26)$ & $0.03(0.22)$ & $0.03(0.07)$ \\
\hline$u_{0 j}$ (intercept) & $162.9(18.4)^{\star}$ & $161.3(18.3)^{\star}$ & $163.5(18.4)^{\star}$ & $163.7(18.4)^{\star}$ & $163.7(18.4)^{\star}$ \\
\hline$\rho_{0,1}$ (age, intercept) & $-3.59(1.23)^{\star}$ & $-3.64(1.23)^{\star}$ & $-3.60(1.23)^{\star}$ & $-3.61(1.23)^{\star}$ & $-3.61(1.23)^{\star}$ \\
\hline$u_{1 j}$ (age) & $0.39(0.11)$ & $0.38(0.10)^{\star}$ & $0.39(0.10)^{*}$ & $0.39(0.10)^{\star}$ & $0.39(0.10)$ \\
\hline$e_{i j}$ & $34.4(2.1)^{\star}$ & $34.5(2.1)^{*}$ & $34.5(2.1)^{\star}$ & $34.5(2.1)^{\star}$ & $34.5(2.1)$ \\
\hline$-2 \times$ loglikelihood & 7813.5 & 7807.1 & 7814.5 & 7814.7 & 7814.6 \\
\hline \multicolumn{6}{|c|}{ Auditory-verbal learning test } \\
\hline$\beta_{0 j}$ & $51.8(4.6)^{\star}$ & $49.9(4.7)^{\star}$ & $48.5(5.7)^{\star}$ & $52.8(5.4)^{\star}$ & $49.5(5.1)^{\star}$ \\
\hline$\beta_{1 j}$ (age) & $-0.57(0.12)^{\star}$ & $-0.57(0.12)^{\star}$ & $-0.56(0.12)^{\star}$ & $-0.57(0.11)^{\star}$ & $-0.57(0.12)^{\star}$ \\
\hline$\beta_{2 j}(\operatorname{sex})$ & $8.64(1.17)^{\star}$ & $8.97(1.14)^{\star}$ & $8.53(1.14)^{\star}$ & $8.61(1.14)^{\star}$ & $8.53(1.14)^{\star}$ \\
\hline$\beta_{3 j}$ (practice) & $4.63(0.69)^{*}$ & $4.63(0.69)^{*}$ & $4.63(0.69)^{\star}$ & $4.63(0.69)$ & $4.63(0.69)^{\star}$ \\
\hline$\beta_{4 j}(\mathrm{TIE})$ & $0.00(0.10)$ & $0.36(0.14)^{\star}$ & $0.24(0.23)$ & $-0.07(0.19)$ & $0.07(0.06)$ \\
\hline$\beta_{5 j}$ (NART) & $0.26(0.06)^{*}$ & $0.25(0.05)^{\star}$ & $0.25(0.05)^{\star}$ & $0.26(0.06)^{*}$ & $0.24(0.06)^{\star}$ \\
\hline$\beta_{6 j}$ (education) & $0.78(0.32)^{\star}$ & $0.73(0.32)^{\star}$ & $0.80(0.32)^{\star}$ & $0.79(0.32)^{\star}$ & $0.76(0.32)$ \\
\hline$\beta_{7 j}(\mathrm{MHT})$ & $0.10(0.06)$ & $0.08(0.06)$ & $0.10(0.06)$ & $0.10(0.06)$ & $0.10(0.06)$ \\
\hline$u_{0 j}$ (intercept) & $91.3(17.7)^{\star}$ & $88.4(17.6)^{\star}$ & $91.9(17.7)^{\star}$ & $91.3(17.7)^{\star}$ & $90.7(17.6)^{\star}$ \\
\hline$\rho_{0,1}$ (age, intercept) & $-2.29(1.61)$ & $-2.25(1.60)$ & $-2.36(1.61)$ & $-2.30(1.61)$ & $-2.26(1.60)$ \\
\hline$u_{1 j}$ (age) & $0.65(0.18)^{*}$ & $0.65(0.18)^{*}$ & $0.65(0.18)^{\star}$ & $0.65(0.18)^{\star}$ & $0.64(0.18)^{\star}$ \\
\hline$e_{i j}$ & $57.1(3.6)^{\star}$ & $57.0(3.6)^{\star}$ & $57.1(3.6)^{\star}$ & $57.1(3.6)^{\star}$ & $57.1(3.6)$ \\
\hline$-2 \times \log$ likelihood & 7781.6 & 7774.9 & 7780.5 & 7781.4 & 7780.1 \\
\hline
\end{tabular}

test and the auditory-verbal learning test (standard points 0.43 (standard error 0.16) and 0.36 (0.14), respectively; both $\mathrm{P}<0.05)$. The total score for typical intellectual engagement was no longer significant after covariant adjustment. For the digit symbol substitution test scores on each occasion, the covariance between the constant $\left(\beta_{0 j}\right)$ and the slope $\left(\beta_{1 j}\right)$ with age was significantly negative, suggesting that higher initial test scores were associated with steeper age related decline. The same was not true for the auditory-verbal learning test scores, where the covariance was not significant.

\section{Discussion}

\section{Statement of principal findings}

We examined the effects of typical intellectual engagement on individual differences in rates of decline on two cognitive measures: the digit symbol substitution test to capture changes in mental speed, and the auditory-verbal learning test to follow changes in verbal memory performance. In our statistical models, we introduced possible confounders available from early life and life course, including scores of childhood intelligence, duration of formal education, and crystallised ability. We also controlled for practice effects associated with repeated testing.

Our results revealed correlations between subtypes of typical intellectual engagement score and late life cognition. For the problem solving domain of typical intellectual engagement and overall typical intellectual engagement, significant associations remained after adjustment for age, sex, and test practice effects. Although typical intellectual engagement was associated with cognitive ability levels in late adulthood, it had no effect on the trajectory of decline over time, which would draw into question one interpretation of the "use it or lose it" conjecture, if "losing it" is interpreted as being functionally inferior to the past. An alternative interpretation would be to define "losing it" as falling below an absolute functional threshold. Here, one could argue that the conjecture may be supported by the main effect of the problem solving domain score on the intercept of cognitive performance scores in later life. Our life course findings are consistent with other studies that have shown associations between typical intellectual engagement and cognition in cross sectional analyses. Engagement in problem solving is an independent contributor to late life cognition and has a unique effect over and above the effect of other life course variables (education, childhood intelligence, and crystallised ability). As expected, age related cognitive decline was observed for both memory and speed of performance.

\section{Strengths and weaknesses of the study}

A particular strength of the current study lies in the generalisability of its results, from a population based 
volunteer sample with good rates of recruitment (75\%) among those eligible. ${ }^{21}$ However, recruitment to and retention in cognitive ageing studies is also affected by self selection to volunteer among better educated individuals who are ageing well, which is also true of our study. Thus, the findings might be biased towards those individuals with higher cognitive performance. The availability of childhood intelligence test scores lies at the heart of our research programme. These archived data remain rare among those individuals now at increased risk of age related cognitive decline. The introduction of the effects of practice is rarely undertaken in cognitive ageing studies, and probably strengthened our design and confidence in our interpretation of results.

Although we were able to gain access to early life mental ability archives, and participants provided details of early life experiences, these data are retrospective and impossible to corroborate in most instances. As life course studies mature in later born cohorts, those currently under investigation will yield observational data collected contemporaneously in a family setting with follow-up over the life course that will reduce the reliance on recollection.

Generally, all ageing studies of this type are hindered by participant dropout, and those individuals who are cognitively declining are more likely not to return for retesting, ${ }^{29}$ which could attenuate any agexTIE interaction effect and could be responsible for our null result.

\section{Strengths and weaknesses in relation to other studies}

Cross sectional studies have shown that routine exercise of intellectual capacities is associated with cognitive advantage. ${ }^{30-32}$ It is, however, impossible for a causal effect to be inferred, and it is possible that cognitive advantage and engagement may be brought about by a shared origin. Here, we were able to postulate and test original ability (and education) as this shared origin, and found that engagement in problem solving is independently associated with cognition in later life. This association suggests that engagement adds to an individual's cognitive reserve $\mathrm{e}^{33}$-that is, individuals who engage in regular problem solving activities might require greater age related neuropathological burdens before clinical thresholds of impairment are crossed and symptoms of cognitive decline are reported. These results indicate that engagement in problem solving does not protect an individual from decline, but imparts a higher starting point from which decline is observed and offsets the point at which impairment becomes significant. The other domains of typical intellectual engagement and the total typical intellectual engagement score are explained by sex and practice gains and early ability measures, indicating that they might not add to passive reserve in the same way.

High scores on the problem solving questions requires a greater level of comfort with novelty which may influence cognitive ageing. ${ }^{34} 35$ For example, Hultsch and colleagues ${ }^{34}$ reported that activities reflecting novel information processing were more predictive of cognition than was overall activity level. More recently, Parisi and colleagues ${ }^{35}$ reported a positive relation between self reported measures of alertness to novelty and intellectual complexity and performance on tests of fluid intelligence. Their findings also suggested that a predisposition towards mental engagement (including a need for cognition engagement, mindfulness, and openness to experience) and activity engagement are distinct constructs that independently contribute to fluid ability. This possible conclusion highlighted the importance of the predisposition towards mental engagement, as well as the habitual tendency to participate in activities that positively influence cognitive ability throughout life.

\section{Meaning of the study: possible explanations and} implications for clinicians and policymakers Our study has several implications concerning the possible role of intellectual engagement in intervention programmes to improve resilience in cognitive ageing studies. Our results indicate that later life intervention to increase activity might not influence the trajectory of decline. The results also suggest that investment in problem solving throughout life could enhance cognitive performance, providing an individual with a higher cognitive point from which to decline.

It is difficult to judge how best to introduce our main findings to those who develop and promote cognitive training programmes to boost cognitive reserve, with the aim of buffering age related cognitive decline. ${ }^{36}$ Evidence for the efficacy of these programmes is limited so far, but the intentions appear laudable with no apparent ill effects.

Studies in child developmental psychology have sought to link research findings modelling normal patterns of development with interventions designed to foster cognitive development and successful social adjustment. Similarly, we believe that a comparable life course approach would be advantageous, such that early interventions to slow or prevent cognitive ageing would capitalise on the covariates identified here and encourage the early acquisition of mentally effortful pursuits and their enduring exercise throughout adulthood.

\section{Unanswered questions and future research}

It is difficult to know whether many older people can increase their brainpower by doing things such as crosswords and Sudoku. Better tests would work out how much intellectual commitment each individual makes when playing and the intensity of that commitment. Personality could govern how much effort older people put into such activities and why. How personality and mental effort are related and how their combined influence affects cognitive performance is unclear. As with all such findings, replication of our results in other samples is essential. In longitudinal analyses of cognitive development (and decline), the "use it or lose it" conjecture can affect the intercept 
(that is, an individual's entry level performance) ${ }^{37}$ as well as the slope of cognitive functioning (that is, an individual's rate of decline) in late adulthood. Future work in the area should clarify the analytical focus of the conjecture, and engagement might be hypothesised to influence the intercept, slope, or both indicators of cognitive performance in late life.

Finally, for those of you struggling to come up with good ideas for Christmas presents for the "developing" adults in your life-although a shiny new chess board, 1000 page Sudoku puzzle book, or all-inclusive tickets to the museum of modern art's quiz night might not influence trajectories of cognitive decline, have no fear. If family and friends give you a disappointed look on opening their Christmas present, remind them that investment in intellectual activities throughout life could provide them with a higher cognitive point from which to decline. Surely, this is as good a gift as any!

We thank the study participants who volunteered their time and efforts to sustaining this long term community project. Lay members of the steering group were recruited and were present at several group meetings; we are grateful for their participation.

Contributors: All authors contributed substantially to the conception and planning of the work that led to the manuscript or acquisition, analysis and interpretation of the data; contributed to the drafting and revision of the manuscript for important intellectual content, and approved the final submitted version of the manuscript; and had full access to all of the data (including statistical reports and tables) in the study and can take responsibility for the integrity of the data and the accuracy of the data analysis. RTS is guarantor and accepts full responsibility for the work and conduct of the study and confirms that he had access to the data, and controlled the decision to publish. The corresponding author attests that all listed authors meet authorship criteria and that no others meeting the criteria have been omitted.

Funding: The Aberdeen Birth Cohort Studies were initiated in 1998 by a grant from the Henry Smith Charity and later supported by the Biology and Biotechnology Science Research Council, the Medical Research Council, Wellcome Trust, Chief Scientist's office of the Scottish Government Health Department, and Alzheimer Research UK. The study sponsor was the University of Aberdeen. The funders and sponsor played no role in the design, data collection, interpretation of the data, writing of the report, and the decision to submit the article for publication.

Competing interests: All authors have completed the ICMJE uniform disclosure form at www.icmje.org/coi_disclosure.pdf and declare: support from the University of Aberdeen for the submitted work; no financial relationships with any organisations that might have an interest in the submitted work in the previous three years; no other relationships or activities that could appear to have influenced the submitted work.

Ethical approval: Ethics permissions were provided by the research ethics committee of University of Aberdeen and NHS Grampian. Volunteers gave written informed consent to a longitudinal observational study of brain ageing and health.

Data sharing: All data are available by application to the Aberdeen Birth Cohort steering group (https://www.abdn.ac.uk/birthcohorts/1921/for-researchers/).

The lead author affirms that the manuscript is an honest, accurate, and transparent account of the study being reported; that no important aspects of the study have been omitted; and that any discrepancies from the study as planned (and, if relevant, registered) have been explained.

This is an Open Access article distributed in accordance with the Creative Commons Attribution Non Commercial (CC BY-NC 4.0) license, which permits others to distribute, remix, adapt, build upon this work non-commercially, and license their derivative works on different terms, provided the original work is properly cited and the use is noncommercial. See: http://creativecommons.org/licenses/by-nc/4.0/.

1 van Oijen M, de Jong FJ, Hofman A, Koudstaal PJ, Breteler MM. Subjective memory complaints, education, and risk of Alzheimer's disease. Alzheimers Dement 2007;3:92-7. doi:10.1016/j. jalz.2007.01.011

2 Solomon A, Kivipelto M, Soininen H. Prevention of Alzheimer's disease: moving backward through the lifespan. J Alzheimers Dis 2013;33(Suppl 1):S465-9. doi:10.3233/JAD-2012-129021

3 Ngandu T, Lehtisalo J, Solomon A, et al. A 2 year multidomain intervention of diet, exercise, cognitive training, and vascular risk monitoring versus control to prevent cognitive decline in at-risk elderly people (FINGER): a randomised controlled trial. Lancet 2015;385:2255-63. doi:10.1016/S01406736(15)60461-5

4 Stanovich KE. Cunningham, Anne E. West, Richard F. Literary Experiences and the shaping of cognition. In: Paris SG, Wellman HM, eds. Global prospects for education: Development, culture, and schooling. American Psychological Association, 1988: 253-88.

Rabbitt P, Lunn M, Wong D. Death, dropout, and longitudinal measurements of cognitive change in old age. J Gerontol B Psychol Sci Soc Sci 2008;63:271-8. doi:10.1093/geronb/63.5.P271

6 Wesnes K, Pincock C. Practice effects on cognitive tasks: a major problem? Lancet Neurol 2002;1:473.

7 Staff RT, Hogan MJ, Whalley LJ. Aging trajectories of fluid intelligence in late life: The influence of age, practice and childhood IQ on Raven's Progressive Matrices. Intelligence 2014;47:194-201. doi:10.1016/j. intell.2014.09.013

8 Van der Elst W, van Boxtel MP, van Breukelen GJ, Jolles J. Rey's verbal learning test: normative data for 1855 healthy participants aged 24-81 years and the influence of age, sex, education, and mode of presentation. J Int Neuropsychol Soc 2005;11:290-302. doi:10.1017/S1355617705050344

9 Staff RT, Hogan MJ, Whalley LJ. The influence of childhood intelligence, social class, education and social mobility on memory and memory decline in late life. Age Ageing 2018;47:847-52. doi:10.1093/ageing/afy111

10 Rowe JW, Kahn RL. Successful aging. Gerontologist 1997;37:433-40 doi:10.1093/geront/37.4.433

11 Ball K, Berch DB, Helmers KF, et al, Advanced Cognitive Training for Independent and Vital Elderly Study Group. Effects of cognitive training interventions with older adults: a randomized controlled trial. JAMA 2002;288:2271-81. doi:10.1001/jama.288.18.2271

12 Christensen $\mathrm{H}$, Korten AE, Jorm AF, et al. Education and decline in cognitive performance: compensatory but not protective. Int J Geriatr Psychiatry 1997;12:323-30. doi:10.1002/(SICI)10991166(199703)12:3<323::AID-GPS492>3.0.CO:2-N

13 Jopp D, Hertzog C. Activities, self-referent memory beliefs, and cognitive performance: evidence for direct and mediated relations. Psychol Aging 2007;22:811-25. doi:10.1037/0882 7974.22.4.811

14 Leibovici D, Ritchie K, Ledésert B, Touchon J. Does education level determine the course of cognitive decline? Age Ageing 1996;25:3927. doi:10.1093/ageing/25.5.392

15 Schaie K. Midlife influences upon intellectualfunctioning in old-age. Int J Behav Dev 1984;7:463-78. doi:10.1177/016502548400700405

16 Stanovich KE, Cunningham AE, West RF. Literacy experiences and the shaping of cognition. In: Paris SG, Wellman HM, ed. Global prospects for education: Development, culture, and schooling. American Psychological Association 1998:253-88

17 Verghese J, Lipton RB, Katz MJ, et al. Leisure activities and the risk of dementia in the elderly. N Engl J Med 2003;348:2508-16. doi:10.1056/NEJMoa022252

18 Stanovich K, West R, Harrison M. Knowledge growth and maintenance across the life-span - the role of print exposure. Dev Psychol 1995;31:811-26. doi:10.1037/0012-1649.31.5.811

19 von Stumm S, Deary IJ. Typical intellectual engagement and cognition in the ninth decade of life: The Lothian Birth Cohort 1921. Psychol Aging 2012;27:761-7. doi:10.1037/a0026527

20 Joy S, Fein D, Kaplan E. Decoding digit symbol: speed, memory, and visual scanning. Assessment 2003;10:56-65. doi:10.1177/0095399702250335

21 Whalley LJ, Murray AD, Staff RT, et al. How the 1932 and 1947 mental surveys of Aberdeen schoolchildren provide a framework to explore the childhood origins of late onset disease and disability. Maturitas 2011;69:365-72. doi:10.1016/j.maturitas.2011.05.010

22 Rey A. L'Examen clinique en psychologie. University of France Press, 1964.

23 Andersson C, Lindau M, Almkvist O, Engfeldt P, Johansson SE, Eriksdotter Jonhagen M. Identifying patients at high and low risk of cognitive decline using Rey Auditory Verbal Learning Test among middle-aged memory clinic outpatients. Dement Geriatr Cogn Disord 2006:21:251-9. doi:10.1159/000091398

24 Tranter LJ, Koutstaal W. Age and flexible thinking: an experimental demonstration of the beneficial effects of increased cognitively stimulating activity on fluid intelligence in healthy older adults. Neuropsychol Dev Cogn B Aging Neuropsychol Cogn 2008;15:184207. doi:10.1080/13825580701322163 
25 Goff M, Ackerman PL. Personality intelligence relations - assessment of typical intellectual engagement. J Educ Psychol 1992;84:537-52. doi:10.1037/0022-0663.84.4.537

26 Chamorro-Premuzic T, Furnham A, Ackerman PL. Incremental validity of the typical intellectual engagement scale as predictor of different academic performance measures. J Pers Assess 2006;87:261-8. doi:10.1207/s15327752jpa8703 07

27 von Stumm S, Hell B, Chamorro-Premuzic T. The hungry mind: intellectual curiosity is the third pillar of academic performance. Perspect Psychol Sci 2011;6:574-88. doi:10.1177/1745691611421204

28 Powell C, Nettelbeck T, Burns NR. Deconstructing intellectual curiosity. Pers Individ Dif 2016;95:147-51. doi:10.1016/j.paid.2016.02.037

29 Staff RT, Chapko D, Hogan MJ, Whalley LJ. Life course socioeconomic status and the decline in information processing speed in late life. Soc Sci Med 2016;151:130-8. doi:10.1016/j. socscimed.2016.01.019

30 Rohwedder S, Willis RJ. Mental Retirement. J Econ Perspect 2010;24:119-38. doi:10.1257/jep.24.1.119

31 Hong SI, Morrow-Howell N. Health outcomes of Experience Corps: a high-commitment volunteer program. Soc Sci Med 2010;71:414-20. doi:10.1016/j.socscimed.2010.04.009
32 Erickson KI, Voss MW, Prakash RS, et al. Exercise training increases size of hippocampus and improves memory. Proc Natl Acad Sci U S A 2011;108:3017-22. doi:10.1073/pnas.1015950108

33 Stern Y. What is cognitive reserve? Theory and research application of the reserve concept. J Int Neuropsychol Soc 2002;8:448-60. doi:10.1017/S1355617702813248

34 Hultsch DF, Hertzog C, Small BJ, Dixon RA. Use it or lose it: engaged lifestyle as a buffer of cognitive decline in aging? Psychol Aging 1999:14:245-63. doi:10.1037/0882-7974.14.2.245

35 Parisi JM, Stine-Morrow EAL, Noh SR, Morrow DG. Predispositional engagement, activity engagement, and cognition among older adults. Neuropsychol Dev Cogn B Aging Neuropsychol Cogn 2009;16:485504. doi:10.1080/13825580902866653

36 Cespón J, Miniussi C, Pellicciari MC. Interventional programmes to improve cognition during healthy and pathological ageing: Cortical modulations and evidence for brain plasticity. Ageing Res Rev 2018;43:81-98. doi:10.1016/j.arr.2018.03.001

37 Bielak AAM. How can we not 'lose it' if we still don't understand how to 'use it'? Unanswered questions about the influence of activity participation on cognitive performance in older age--a mini-review. Gerontology 2010;56:507-19. doi:10.1159/000264918

Web appendix: Supplementary materials 